\title{
Clients' perceptions of an occupational therapy intervention at a substance use rehabilitation centre in the Western Cape
}

\author{
Teneil Bell, BScOT (UWC), MECI (UP) \\ Lecturer, Department of Occupational Therapy, University of the Western Cape
}

\section{Lisa Wegner, PhD (UCT)}

Associate Professor and Chairperson, Department of Occupational Therapy

University of the Western Cape

Lauren Blake, BSc OT (UWC)**

Leigh Jupp, BSc OT (UWC)**

Fides Nyabenda, BSc OT (UWC)**

Tamryn Turner, BSc O T (UWC)**

*** Occupational therapy students, Department of Occupational Therapy, University of the Western Cape 20I2, at the time the research was undertaken

Substance use among adolescents is a significant health and social problem and affects occupational performance. While occupational therapy interventions are available at substance use rehabilitation centres in the Western Cape, little is known about clients' perceptions of the usefulness of these interventions. A qualitative study was conducted to address this gap, specifically exploring clients' perceptions of the usefulness of the intervention on their occupations post discharge. The occupational therapist at a particular centre was interviewed as a key informant. Eight participants who attended the aftercare programme at the centre took part in three focus groups. Four themes emerged from the analysis of data: "We taking the drugs away, but we need to give them something back in that place"; "I don't want to be that person I was in the past"; "Keeping me clean"; "Take us out into the life". Participants perceived skills development, work training, life skills and leisure exploration to be useful. However, team members' roles and treatment objectives should be clarified to the clients to ensure that clients understand why they are participating in therapy. Finally, there should be more community-based, out-patient support programmes for adolescents so that the appropriate services are more easily accessible.

Key words: At-risk youth, client perspectives, occupational therapy intervention, substance use intervention, Western Cape

\section{INTRODUCTION}

Currently, substance use among adolescents is a global phenomenon and is fast reaching an unmanageable state'. In South Africa, the mean age of patients admitted to substance use treatment centres is decreasing ${ }^{\prime}$, reflecting an increase in drug use by adolescents and even children. Morojele et al. ${ }^{2}$ show that the Western Cape had significantly higher rates of current cigarette, alcohol, and cannabis use and alcohol bingeing than the national average, increasing the risk of health and social problems related to substance use. Substance use among adolescents is one of the most significant health and social problems ${ }^{3}$ and affects occupational performance.

While there are various occupational therapy intervention programmes at substance use rehabilitation centres in the Western Cape, little is known about how the clients experience the intervention provided. The researchers identified the need to understand which elements of the occupational therapy intervention programme at a substance use rehabilitation centre in the Western Cape were useful in optimising occupational performance. To foster the researchers' understanding of the occupational therapy intervention, they focused on the clients' experiences, as this allowed the researchers to identify the participants' personal views when providing feedback on the intervention programme. Therefore the study addressed the following research question: what are the clients' perceptions of the usefulness of an occupational therapy intervention at a substance use rehabilitation centre in Cape Town?

\section{STUDY SETTING}

The study was based at an in-patient treatment facility located in the Western Cape specialising in at-risk youth with substance abuse diagnoses. The cliental of the centre are obtained from referrals from the Department of Social Development, from court committals or court diversions as well as voluntary admissions. The clients at the centre range in age from 12 to 18 years; however, their education level is often lower than expected for their age. The in-patient programme runs over a period of eight weeks, with the emphasis on bio-psychosocial functioning and educational reintegration. A bio-psychosocial approach implies that an etiology of a disease or illness has biological, psychological and sociological determinants such as genetic, developmental and environmental factors ${ }^{4}$. The multidisciplinary team includes occupational thera- 
pists, psychologists and social workers. The centre aims to provide individualised therapy to promote a client centered practice with therapy sessions being both individual and group based. In addition to the in-patient programme, an out-patient aftercare programme functions as a support group for both parents and adolescents and runs every Saturday morning over a period of six months after discharge from the centre.

The role of the occupational therapist within the centre is focused on preparing the clients for community integration on discharge by equipping them with the skills to stay clean from substance use. Due to the high client load, the occupational therapist is assisted by trained care workers. The occupational therapy intervention offers leisure exploration and participation (tennis, soccer, swimming, karate and boot camp), relaxation therapy, life skills (self-identity, self-concept, communication, problem solving and goal setting), arts and crafts, and skills development (beauty therapy, welding, gardening, haircutting and basic self-defence). Thereby the intervention aims to address the occupational deficits created by substance use by providing opportunities for the clients to engage in meaningful and purposeful occupation. The occupational therapist further aims for the intervention to promote health and wellbeing.

\section{LITERATURE REVIEW}

Occupational performance refers to the accomplishment of a selected occupation or activity and occurs through a dynamic transaction between the person, the context, and the activity ${ }^{5}$. Furthermore it involves the roles, tasks and activities that allow the individual to organise his/her daily occupations ${ }^{6}$. Helbig and McKay ${ }^{7}$ state that dysfunctional occupational performance may be a consequence of engaging in addictive behaviours and may give rise to ill health and social problems. People who engage in substance use neglect their daily roles, tasks and activities as the activity of substance use consumes their time and interest.

The occupational performance of adolescents using substances is negatively affected and can affect age related occupations such as attending school and socialisation ${ }^{8}$. Sutherland and Shepherd describe how adolescent alcohol and drug use are associated with academic difficulties, declining grades, absenteeism, and school drop-out. While the substance use has an impact on the adolescent's current occupational performance, it also influences the rest of an adolescent's life ${ }^{10}$. This disturbance in occupational performance, health and well-being and age appropriate occupational engagement shows the need for occupational therapy intervention.

Occupational therapy intervention is an important part of substance use rehabilitation programmes as it enables clients to foster engagement in meaningful occupations and activities ${ }^{8}$. Furthermore, it assists clients with planning and structuring their time to focus on constructive, meaningful activities and occupations which replace drug-related activities ${ }^{\prime 1}$. Wegner ${ }^{12}$ states that the focus of occupational therapy intervention with drug-related disorders is on lifestyle and behaviour change which occurs mainly through group work. During group work intervention, occupational therapists make use of the therapeutic factors inherent in groups such as instillation of hope, universality, identification, altruism and

Table I: Summary of participants

\begin{tabular}{|l|c|c|c|c|}
\hline Participant & Gender & Age & Substances Used & Attending School currently \\
\hline Participant I & Girl & 15 & Cannabis, Methamphetamine, Mandrax & Yes \\
\hline Participant 2 & Boy & 17 & Methamphetamine, Mandrax & No \\
\hline Participant 3 & Girl & 18 & Cannabis, Methamphetamine, Mandrax & No \\
\hline Participant 4 & Boy & 17 & Cannabis, Methamphetamine, Mandrax & No \\
\hline Participant 5 & Girl & 15 & Cannabis, Methamphetamine, Mandrax & No \\
\hline Participant 6 & Boy & 16 & Cannabis, Methamphetamine & No \\
\hline Participant 7 & Boy & 17 & Cannabis, Methamphetamine & No \\
\hline Participant 8 & Boy & 18 & Cannabis, Methamphetamine, Mandrax & No \\
\hline
\end{tabular}
occupations post discharge. interpersonal learning ${ }^{13}$ to shape the desired behaviour that they would like to elicit in each group member. To further facilitate personal change, occupational therapy intervention aims to enable clients to recognise the problem and its consequences, admit the need for help, and concentrate on learning to live with the problem in a constructive manner ${ }^{12}$.

However, few studies ${ }^{8,14}$ have evaluated occupational therapy intervention programmes and examined the efficacy and effectiveness of interventions. Visser and Moleko ${ }^{15}$ state that interventions have to be properly managed by identifying and acknowledging strengths and weaknesses as this allows for sustainability. There is a need for research that evaluates the usefulness and effectiveness of occupational therapy interventions, specifically in substance use rehabilitation centres, in order to promote practice that is evidence based. The profession of occupational therapy needs evidencebased research to verify how and why they provide the kind of intervention they do. Therefore, the purpose of the current study was to explore the perceptions of adolescents who were admitted to a substance use rehabilitation centre about the usefulness of the occupational therapy intervention, and the influence on their daily

\section{METHODOLOGY}

\section{Study design}

A qualitative approach ${ }^{16}$ was used to explore adolescents' perceptions of an occupational therapy intervention at a youth substance use rehabilitation centre in the Western Cape. Hammell, Carpentar and Dyck ${ }^{16}$ explain that within qualitative research the belief is that people are inseparable from their contexts and their environments and it therefore examines the meanings attributed to events by human beings. Within the qualitative paradigm an exploratorydescriptive research design was used in order to achieve the objectives of the study ${ }^{17}$.

\section{Participants}

Using purposeful sampling ${ }^{16}$ eight participants were selected for the study (Table $I$ ). The inclusion criteria stipulated that the participants must be regular attendees of the aftercare programme held every Saturday morning and have an education level of at least grade seven. While all the participants had reached this level of education, only one participant was still attending school. The selected participants ranged in age from 15 - 18 years. Furthermore the resident occupational therapist at the rehabilitation centre was invited to be a key informant for the study, in order to draw on her knowledge, expertise, experience and observations gained whilst working at the rehabilitation centre.

\section{Data Collection}

Two methods of data gathering were used, namely an in-depth interview with the key informant and three focus groups with the participants. The key informant interview was conducted prior to the focus groups in order to refine the question guide designed by the researchers. The focus groups were run with the eight participants on consecutive Saturdays at the treatment facility. Cook ${ }^{18}$ explains that focus groups are an effective data collection tool as they promote group interaction and enable a maximum range of topics to be covered. Both the interview and focus groups were video-taped and later transcribed verbatim. One researcher facilitated the focus group, another co-facilitated and the two remaining researchers were observers. A semi-structured interview guide was used during the 
focus groups to explore the usefulness of the occupational therapy intervention. The participants were asked about their positive and negative experiences of the occupational therapy intervention, and what aspects of the intervention they found useful after their discharge. Due to time constraints within the study only three focus groups could be arranged, however saturation was reached during the third focus group which served as member checking.

\section{Data Analysis}

Data was analysed using thematic analysis ${ }^{19}$ with the researchers first identifying units of meaning, and then grouping these into categories. Finally themes were identified by grouping similar categories. During data analysis the transcripts were analysed independently by the researchers and then discussed. As a method of ensuring trustworthiness ${ }^{20}$ in the study, member checking was completed at the end of the data analysis period by validating the findings of the study with the group of participants. The compilation of an audit trail from the gathered data of reflective journals, field notes, audiotapes, time lines, supervisors' feedback and informal discussions assisted the researchers in formulating their findings. Furthermore, a level of reflexivity was ensured through reflective journaling by each group member throughout the research process and aided discussions and analysis.

\section{Ethics}

The Research Ethics committee at the University of the Western Cape gave ethical approval for the study. The Centre Manager gave permission for the study to be conducted at the centre. The adolescents' parents were provided with information letters and gave written consent, and the participants' written assent was obtained. Participants took part voluntarily, were aware that they could stop participating at any time, and were assured of confidentiality. There was no remuneration for participating in the study.

\section{FINDINGS}

Four main themes emerged from the analysis of data: (I) "We taking the drugs away, but we need to give them something back in that place"; (2) "I don't want to be that person I was in the past"; (3) "Keeping me clean"; (4) "Take us out into the life".

\section{"We taking the drugs away, but we need to give them something back in that place"}

The above quote was captured from the interview with the key informant but was a theme echoed by the participants during the focus groups. It highlights that the focus of the occupational therapy intervention was on occupation and skills-based therapy. This theme further discussed the role of occupational therapy within the multidisciplinary team and the clients' perceptions of the occupational therapy programme overall and the team members.

The role of the occupational therapist in the centre as identified by the key informant is diverse, with the main aim being community reintegration. The occupational therapist stated that she is not able to provide direct therapy to all clients in all sessions and therefore she is responsible for training care workers to implement occupational therapy based interventions. Additionally she also stated that her role is to conduct assessments, provide opportunities for exploring alternative leisure activities, and implement skills development which includes beauty therapy, welding, gardening and basic self-defence.

"It's a positive alternative use of free time, showing them the positive use of free time. It's giving them skills for the open job work market..." (Key informant)

The key informant also noted the various events such as talent shows and sport days and the benefits of these activities in terms of building adolescents' confidence.

"We do talent shows, sports days, we do plays on Workers Day we did... the children had to do work skits and they bring their real life into it so their drugging life into their plays and role plays. And it's so nice and it helps them grow, and it helps build their self-confidence." (Key informant)

The participants were unsure of the roles of each team member and thus the specific role of the occupational therapist. They were able to identify elements of the occupational therapy intervention such as sports, arts and crafts groups and skills development but struggled to conceptualise the intervention as a whole. This lack of role identity may have added to the participants' perceptions of the arts and crafts group. Most participants were unable to identify the reasoning and value behind arts and crafts groups and two participants stated that they would rather do acting or drama.

"... arts and crafts was extremely boring, we traced flowers and all that stuff." (I6 year old boy)

\section{"Keeping me clean"}

This theme captures the main reason the participants entered rehabilitation which is to directly deal with the addiction and develop skills to continue to deal with it once discharged. The categories explore the skills the participants learned in the occupational therapy intervention which included social and vocational skills development, dealing with cravings, and staying away from substances.

An important skill that the participants felt they developed was that of effective communication. Most of the participants perceived that one reason they had stayed clean from substance use was that they were now communicating their feelings.

"Like me when I was on drugs I never use to even talk to my mommy I would just say l'm hungry and ask for money and so on. But now that I'm not using [drugs] anymore, I can talk to my mom about everything that is happening in my life." ( 16 year old boy)

When participants had no one to communicate with once discharged they used other skills taught to them in the programme such as journaling as a way to express their feelings.

"Journaling helps me often and always because I write in my book and I write if my mommy is not by me now and I really need someone to talk to. I write because it's not funny if you write and stuff, because it helps me. I don't wanna carry all this heavy stuff on my shoulder. That is why I empty my baggage." (I 5 year old girl)

The journaling was also identified as a tool to help them to deal with cravings as it helped them express their inner emotions, which is a major part of the rehabilitation process for all the participants.

The participants identified the vocational skills development as being useful as they used these skills to gain income and keep clean from substance use. These work skills included welding, beauty therapy (manicures, pedicures and facials), and haircutting.

"I am doing welding that I learnt here (the Centre) with my dad now." ( 17 year old boy)

The life skills intervention addresses self-identity, self-concept, communication, problem solving as well as goal setting to prepare adolescents for when they are reintegrated into their communities. Although their communities had not changed and their friends still engaged in substance use, the participants perceived that they were able to stay away from substances and expressed that they utilised the life skills such as assertiveness, to do this.

"I tell my friends I don't wanna smoke and what gonna happen cause if I'm gonna smoke again I'm gonna make a whole mess up and it gonna lead me down the drain." (I7 year old boy)

\section{"I do not want to be that person I was in the past"}

This theme captures the participants' perceptions about how they were before they progressed through the intervention programme, how their relationships with their family were at stake, and how their roles were affected whilst on drugs compared with their new roles and interests and the simple tasks that they performed in order to gain the respect and trust of their relatives post-discharge. The 
participants perceived that they had developed various new interests following discharge from the rehabilitation programme. One participant shared his new interests since leaving the rehabilitation programme in this quote:

"I wasn't really interested before but now I am... I'm doing soccer and sport." (I 7 year old boy)

Another participant explained that he now has time for relationships with the opposite sex which he did not have in the past. He explained that these relationships were meaningful and kept him focused to not go back to substances.

“...I never had time for girls when I was on drugs but now that I'm off relationship with girls become so important." ( 15 year old boy)

In order to reintegrate back into their families post discharge, participants spoke about the need to rebuild trust. Participants spoke about doing small things such as bringing small change back, and not taking things that didn't belong to them to show their family and friends that they had changed and that they could be trusted. One of the participants shared her experience of graining trust with her family.

"But now if they ask me to go buy I go buy but I bring their change back. Then they think yaaw.... Then they say to me do you remember the days when you never use to give me my change back... Then I give them their money back and they even count it and then when they get the correct change back they think no man she isn't like that anymore." (I5 year old girl)

The participants shared how their families noticed a change in them since going through the rehabilitation process. For the participants, making these small changes assisted them to re-build and develop relationships with both their friends and family. For most participants having the support from family is of utmost importance to them and that is what is truly helping them stay away from substances.

"Nothing just my family is helping me stay clean by just talking to them about serious stuff." (16 year old boy)

The participants also shared that they became aware of the roles they had lost as a result of using substances during the rehabilitation programme and this assisted them to realise that they did not want to use substances anymore. The main role loss that they identified was their role as learners as many had left school due to drug use.

"...because some of the stuff is complicated cause when I went to rehab I came out in the June holidays then they said I can't go back [to school] because I missed the June exams so now no other school will accept me." (I5 year old girl)

\section{"Take us out into the life"}

The focus of this theme is the key informant and the participants' views for possible changes in the intervention programme, and comprises the following categories: different programme ideas, and community changes. Participants felt that they needed more practical experiences outside the rehabilitation centre to practise their skills learnt during group intervention. The participants explained that it is easier to remember a group skill learnt practically than to remember an entire group discussion. The quote below highlighted their views for possible changes.

“...it will be better if we can practise group stuff on the outside first, while we in here, so that we can know it work and so that if I have questions I can ask." ( 8 year old girl)

A key finding was the need for provision of substance use facilities within communities. The occupational therapist perceived that an essential part of her role was community integration. The participants felt that a better community support system would possibly allow for longer abstinence from substances post discharge. One participant who has been through the substance use programme for a second time, stated:
"...If I had to see someone more in our community all of us would stay clean for longer...." (16 year old)

\section{DISCUSSION}

The present study sought to explore adolescent clients' experiences of an occupational therapy intervention in a substance rehabilitation centre in order to identify what elements they found useful and how this facilitated their occupational performance post discharge. Overall it can be seen that the participants felt they benefited more from practical skills that they could immediately transfer into their own lives. In support of the findings of the study, Waldron and Kaminer ${ }^{21}$ state that behavioural treatment was shown to be superior to supportive counselling in terms of reducing drug use and drugrelated problems.

The first element the participants found helpful was within the life skills programme. Here communication and assertiveness skills were highlighted by the participants as being most beneficial in staying clean. Bhana et al. ${ }^{22}$ reveal that "the focus of strengthening the resilience of adolescents to resist negative peer influences is through improving self-esteem and self-efficacy, particularly with regards to assertive and refusal communication skills"22:33. The findings highlighted the participants' realisation of the importance of communicating with the people close to them such as their family. The importance of family involvement was shared by Stoffel and Moyers ${ }^{8}$ who found that clients who received family intervention were able to rebuild interpersonal relationships with their family members that they had lost while being on drugs. They found that clients that were discharged from rehabilitation centres and attended aftercare where family intervention was included had a greater chance of not relapsing for a year, than clients that had individual intervention only ${ }^{8}$. Journaling was another type of communication style that the adolescents found useful as they learnt how to express their feelings such as anger through journaling instead of bottling emotions up inside of them.

However, in the theme 'Take us out into the life', the participants wanted a more practical approach to learning life skills, suggesting that they be encouraged to practise these skills when they go home over weekends.

The second element the participants found useful was the leisure exploration groups. Leisure is defined as "a non-obligatory activity that is intrinsically motivated and engaged in during discretionary time, that is, time not committed to obligatory occupations such as work, self-care, or sleep"23:250. While the majority of the participants identified that they participated in leisure previously, all stated that due to their use of substances, they stopped engaging in these activities because substance use became all that they did. Being part of the intervention process the participants were reintroduced to sporting and leisure activities, such as soccer and dancing. This engagement in leisure contributed to their feelings of satisfaction and overall health by providing new interests.

The next element that the participants found useful was the vocational exploration. The occupational therapy intervention focused more on vocational skills than scholastic performance due to the clients' ages and contexts. Work includes activities needed for engaging in remunerative employment or volunteer activities ${ }^{24}$. This skills development programme assisted some participants with finding employment after discharge. An unforeseen advantage was that it helped the participants to bond with family members. Winters ${ }^{25}$ states that generally within adolescent substance use rehabilitation centres, there is less emphasis on work and more emphasis on education, including actual schoolwork. But the findings of this study point to the fact that skills development and work training are of vital importance. Williams and Chang ${ }^{26}$ state that the involvement of adolescents in work and school, association with non-using friends, and involvement in leisure activities were outcomes that substance use treatment centers in America provided.

The participants also highlighted the negatives of the intervention. They saw no value in the arts and crafts groups and perceived these to be boring. This can be attributed to the participants not 
clearly understanding why they were attending these group sessions. Additionally, the participants regarded the multi-disciplinary members as counsellors and could not identify them according to their professional identity. They therefore had difficulty identifying the specific occupational therapy role.

Participants felt that they needed support groups in their community to stay clean. Finlay ${ }^{27}$ explains that support groups are made up of communication and psychotherapy which involve sharing experiences and gaining insight respectively. While aftercare was provided at the centre, many participants could not attend due to living far away and financial constraints.

The recommendations from the study focused on aspects of the rehabilitation programme which can be improved as well as a need for community-based therapy. Firstly the clients need more practical experiences outside the programme to practise the skills learned within the programme. Team members' roles and treatment objectives should be clarified with the clients to ensure that they understand why they are participating in therapy. Within the community there is a need for more community-based, out-patient support programmes for adolescents so that the appropriate services are more easily accessible.

The main limitations identified in the study was in relation to time constraints specifically during the participant sampling phase of the study. Firstly there was difficulty in gaining consent from the parents/ guardians of the adolescents attending the aftercare program and resulted in the willing adolescents being excluded. This also resulted in the participant group being predominantly male and therefore the study did not provide a thorough exploration of female perceptions.

\section{CONCLUSION}

The study highlighted adolescent clients' perceptions about the aspects of an occupational therapy intervention at a substance use rehabilitation centre that they found useful after discharge. It also revealed areas of practice that could be strengthened. The key findings of the study revealed that an important motivator for the participants to stay clean after reintegration into their communities was that of restoring and maintaining the roles they had lost. The other main finding was that the participants were of the opinion that the distance of their homes from the rehabilitation centre, was a hindrance. They believed a support group or a social worker within their own communities would assist and be an advantage in the recovery process. This study furthermore highlights the importance of gaining the perceptions of the clients' experiences to understand the usefulness of intervention programmes. Also, this study provided insight into identifying key elements required of an occupation-based drug abuse rehabilitation programmes for adolescents.

\section{ACKNOWLEDGEMENTS}

The authors wish to thank the Centre for allowing us to conduct the study, as well as the occupational therapist and the adolescents for their participation in the study.

\section{REFERENCES}

I. Parry CDH, Meyer B, Morojele, NK, Flisher, AJ, Bhana A, Donson $\mathrm{H}$, Pluddemann A. Trends in adolescent alcohol and other drug use: Findings from three sentinel sites in South Africa. Journal of Adolescence, 2004; 27: 429-440.

2. Morojele N, Myers B, Townsend L, Lombard C, Plüddemann A, Carney T, Petersen Williams P, Padayachee T, Nel E, Nkosi S. Survey on substance use, risk behaviour and mental health among Grade 8-10 learners in Western Cape Provincial Schools, 201 I. Cape Town: South African Medical Research Council, 2013.

3. Flisher AJ, Parry CDH, Evans J, Muller A, Lombard C. Substance use by adolescents in Cape Town: Prevalence and correlates. Journal of Adolescent Health, 2003; 32: 58-65

4. Stein F, Cutler SK. Psychosocial occupational therapy- A holistic approach. New York: Thomson Learning, 2002.

5. American Occupational Therapy Association. Occupational therapy practice framework: Domain and process. American Journal of Oc- cupational Therapy, 2002; 56: 609-639.

6. Crouch R, Alers V. Occupational Therapy in Psychiatry and Mental Health. $4^{\text {th }}$ edition. London: Whurr Publishers LTD, 2005.

7. Helbig K, McKay E. An exploration of addictive behaviours from an occupational perspective. Journal of Occupational Science, 2003; 10(3): 140-145.

8. toffel VC, Moyers PA. An evidence-based and occupational perspective of interventions for persons with substance-use disorders. American Journal of Occupational Therapy, 2004; 58(5): 570-586.

9. Sutherland I, Shepherd JP. Social dimensions of adolescent substance use. Addiction, 200I; 96: 445-458.

10. Visser M, Routledge LA. Substance abuse and psychological wellbeing of South African adolescents. South African Journal of Psychology, 2007; 37(3): 595-6I5.

II. Ozechowski TJ, Liddle HA. Family-based therapy for adolescent drug abuse: Knowns and unknowns. Clinical Child and Family Psychology Review, 2000; 3(4): 269-298.

12. Wegner L. Occupational Therapy intervention for drug-related disorders. In: Crouch R, Alers V. editors. Occupational Therapy in Psychiatry and Mental Health. $4^{\text {th }}$ edition. London: Whurr Publishers, 2005: 537-55I.

13. Yalom ID. The theory and practice of group psychotherapy. $4^{\text {th }}$ edition. New York: Basic Books Inc., 1985.

14. Myers B, Louw J, Fakier N. Alcohol and drug abuse: removing structural barriers to treatment for historically disadvantaged communities in Cape Town. International Journal of Social Welfare, 2008; 17: 156-65.

15. Visser M, Moleko A. Community Psychology in South Africa. South Africa: Van Schaik Publishers, 2012.

16. Hammell KW, Carpenter C, Dyck I. Using qualitative research: A practical introduction for occupational and physical therapists. London: Harcourt Publishers Limited, 2000.

17. Polit D, Beck C. Nursing research: Principles and methods. Philadelphia: Lippincott Williams \& Wilkins, 2004.

18. Cook JV. Qualitative research in occupational therapy: Strategies and experiences. Canada: Delmar Thomson Learning, 200I.

19. Henning E. Finding your way in qualitative research. Pretoria: Van Schaik Publishers, 2009.

20. Krefting L. Rigor in qualitative research: The assessment of trustworthiness. American Journal of Occupational Therapy, 1991; 45(3): 214-22.

21. Waldron HB, Kaminer Y. On the learning curve: The emerging evidence supporting cognitive behavioural therapies for adolescent substance abuse. Addiction, 2004; 99(2): 93-105.

22. Bhana A, Petersen I, Mason A, Mahintsho Z, Bell C, McKay M. Children and youth at risk: Adaptation and pilot study of the CHAMP (Amaqhawe) programme in South Africa. African Journal of AIDS Research, 2004; 3(I): 33-4I.

23. Parham LD, Fazio LS. Play in occupational therapy for children. St Louis: Mosby, 1997.

24. American Occupational Therapy Association. Occupational therapy practice framework: Domain and process $\left(2^{\text {nd }}\right.$ ed.). American Journal of Occupational Therapy, 2008; 62: 625-683.

25. Winters KC. Treating adolescents with substance use disorders: An overview of practice issues and treatment outcome. Substance Abuse, 1999; 20(4): 203-225.

26. Williams RJ, Chang SY. A comprehensive and comparative review of adolescent substance abuse treatment outcome. Clinical psychology: Science and practice, 2000; 7: 138-166.

27. Finlay, L. Groupwork. In: Creek J. editor. Occupational therapy and mental health. Yorkshire: Churchill, Livingstone, 2002.

Corresponding author

Teneil Bell

Department of Occupational Therapy

University of the Western Cape

Robert Sobukwe Road, Bellville, 7535, Republic of South Africa

Email: tbell@uwc.ac.za 